\title{
МОЛОДАЯ ФИЛОЛОГИЯ
}

DOI 10.37386/2305-4077-2020-2-129-136

\author{
А. Г. Ершов ${ }^{\mathbf{1}}$ \\ Российский государственный педагогический университет им. \\ А. И. Герцена
}

\section{ХУДОЖЕСТВЕННОЕ ПЕРЕОСМЫСЛЕНИЕ ОБРАЗОВ РЕАЛЬНЫХ ЛИЦ В «ВЫБРАННЫХ МЕСТАХ ИЗ ПЕРЕПИСКИ С ДРУЗЬЯМИ》 Н. В. Гоголя}

Статья посвящена особенностям использования Н. В. Гоголем образов реальных лиц в работе над книгой «Выбранные места из переписки с друзьями» (1847). Так, на примере главы XXIII «Исторический живописец Иванов» прослеживается путь трансформации образа художника А. А. Иванова в образ «идеального творца», который автор использовал для иллюстрации своих эстетических воззрений. Это, в частности, доказывается сравнением гоголевских писем к А. А. Иванову с текстом посвященной ему главы. На основании проведенного анализа устанавливается, что писатель переосмыслил образ художника как прототип образа «идеального творца» для подтверждения эстетикофилософской концепции книги.

Ключевые слова: Н. В.Гоголь, А.А.Иванов, «Выбранные места из переписки с друзьями», прототипы, художественный образ, документальные материалы, гоголевская эстетика 1840-х годов.

\section{A. G. Ershov}

The Herzen State Pedagogical University of Russia

\section{ARTISTIC RETHINKING OF REAL PERSONS' IMAGES IN N. V. Gogol's «SELECTED PASSAGES FROM CORRESPONDENCE WITH FRIENDS》}

The article is concerned with the features of N. V. Gogol's use of images of real persons in his work on the book "Selected Passages from Correspondence with Friends" (1847). Thus, the example of Chapter 23, "History Painter Ivanov", traces the way of transformation of the image of the artist A.A. Ivanov into the image of the "ideal creator", which the author used to illustrate his aesthetic views. Considerable attention is paid to comparing the real Gogol's correspondence addressed to A. A. Ivanov with the text of the chapter dedicated to the artist. Based on the analysis, it is established that Gogol uses the real person's image to implement the aesthetic and philosophical concept of his book.

Keywords: N. V. Gogol; A. A. Ivanov; prototype; artistic image; documentary materials; Gogol's aesthetics of the 1840s; "Selected Passages from Correspondence with Friends".

1 Артём Геннадьевич Ершов, аспирант кафедры русской литературы Российского государственного педагогического университета имени А. И. Герцена. 
В книге «Выбранные места из переписки с друзьями» (1847) исторические лица и современники автора предстают и полноценными персонажами, и адресатами как прямых, так и косвенных отсылок. Однако эти созданные Гоголем образы зачастую весьма далеки от своих прототипов, поскольку они переосмысливались автором для более точного выражения его позиции по тому или иному вопросу. Мы рассмотрим эту особенность на примере трансформированного образа художника Александра Андреевича Иванова (1806-1858). Именно его характер, творчество, отношения, поступки послужили основой для создания принципиально важного для писателя образа идеального творца. Поэтому мы уделим основное внимание анализу XXIII главы «Исторический живописец Иванов» в книге Гоголя.

Писатель познакомился с А.А.Ивановым в Риме, во время первой поездки в Италию. Однако дата их первой встречи неизвестна. Гоголь приехал в Рим 26 марта 1837 г. и поселился по адресу: Via di San Isidoro, $16^{2}$. Домовладельцу Джованни Мазуччо принадлежало и несколько домов поблизости, где снимали комнаты многие члены русской колонии, в том числе художник Орест Кипренский. Таким образом, уже с начала пребывания в Риме Гоголь входит в тот круг, с которым был постоянно связан А. А. Иванов. Биограф художника относит его знакомство с Гоголем к последним месяцам 1838 г., когда в письмах Иванова впервые появляется имя писателя [Боткин, 1880, с. 9].

Тогда, после завершения картины «Явление Христа Марии Магдалине», Иванов был всецело занят новым трудом - «Явлением Мессии» (так он называет это полотно во время работы). Воплощая свой замысел, он испытывает постоянные затруднения, о чем и сообщает отцу - например, в новогоднем письме от 1 января 1837 г.: «Как трудно придумать эпизоды в мою картину, по сию пору недоволен ими. А когда же буду доволен? Помощи просить едва ли у кого можно. Кто захочет для меня так глубоко входить во все подробности моего предмета» [Боткин, 1880, с. 102]. Знакомство же с Гоголем, также занятым в то время работой над масштабным трудом - поэмой «Мертвые души», скоро переросло в дружбу. За короткое время писатель стал для Иванова самым близким и авторитетным человеком. В письмах к отцу 1841 г. художник называет Гоголя «лучшим нашим литератором», а также «человеком необыкновенным, имеющим высокий ум и верный взгляд на искусство» [Боткин, 1880, с. 137]. Эти слова воспринимаются как глубоко обдуманный вывод многих встреч и бесед. Иванов отмечает не только высокий ум, но и верный взгляд на искусство, что, вероятно, соответствовало ви́дению самого художника. Общение Иванова с Гоголем не прекращалось и во время отъездов писателя из Рима: оно продолжалось в переписке. Причем ее тематика охватывала различные вопросы - не только эстетические, но и бытовые (художник откровенно сообщал писателю о своих житейских затруднениях, связанных с постоянными угрозами лишить его казенного пенсиона и возвратить на родину до окончания работы над картиной «Явление Мессии»). Примечательно, что всё это нашло отражение в главе «Исторический живописец Иванов».

${ }^{2}$ Подробнее о гоголевских адресах в Риме см.: [Золотусский, 1988]. 
Таким образом, дружба Гоголя с художником и живое участие писателя в его творческих планах очевидны: продолжительная переписка, последующая работа Иванова над портретом Гоголя, посещение писателем мастерской художника и непосредственное обсуждение эскизов (биографы сообщают о том, что Гоголь способствовал появлению на картине фигуры раба, отсутствовавшей в ранних эскизах художника, а также о намерении Иванова изобразить Гоголя в образе одного из персонажей на полотне) и, наконец, введение XXIII главы, посвященной живописцу, в «Выбранные места...»-всё это свидетельствует об их близком общении и творческом контакте.

Однако в той же главе Гоголь не столько воссоздает реальную картину жизни А.А.Иванова, сколько конструирует образ, необходимый для общей концепции книги, домысливая факты из его жизни, дополняя его образ теми чертами, которые виделись писателю принципиально важными при изображении творца. Так, в одном из фрагментов Гоголь пишет о его картине: «Весь Рим начинает говорить гласно, судя даже по нынешнему ее виду, в котором далеко еще не выступила вся мысль художника, что подобного явленья еще не показывалось от времен Рафаэля и Леонардо-да-Винчи» (VIII, с. 335) 3 . На самом деле это утверждение не соответствовало действительности. Даже много позже, во время первой выставки картины в российской Академии художеств, она была воспринята довольно холодно и не была понята многими современниками художника ${ }^{4}$. Тем не менее, пока работа над полотном еще продолжалась, гоголевский отзыв о нем в «Выбранных местах...» мог повлиять на создание благоприятного впечатления у будущей публики. Примечательно, что несоответствие созданного писателем образа Иванова-персонажа его прототипу (с идеализацией первого), по воспоминаниям П. М. Ковалевского, в 1856 г. (за два года до первой выставки «Явления Мессии») отметил сам художник: «Николай Васильевич сделал мне много вреда похвалами: после его слов я не вправе выставить свою картину... С меня слишком много спросится» [Боткин, 1880, с. 231].

Интерес представляет также сравнение фрагментов XXIII главы с фрагментами писем Гоголя к Иванову, ибо там писатель не идеализирует художника и порой обращается к нему откровенно критически: «Словом, вbl еще далеко не христианин, хотя и замыслили картину на прославленье Христа и христианства»; «...пока с вами или, лучше, в вас самих не произойдет того внутреннего события, какое силитесь вы изобразить на вашей картине в лице подвигнутых и обращенных словом Иоанна Кр<естителя>, поверьте, что до тех пор не будет кончена ваша картина. Работа ваша соединена с вашим душевным делом. А покуда в душе вашей не будет кистью высшего художника начертана эта картина, потуда не напишется она вашею кистью на холсте. Когда же напишется она на душе вашей, тогда кисть ваша полетит быстрее самой мысли» [Переписка, 1988 , т. II, с. 452; с. 455],- и т.д.

\footnotetext{
3 Здесь и далее в цитатах везде, где специально не обозначено, шрифт изменен мной.-А.Е.

${ }^{4}$ Подробнее об этом см., например: [Виноградов, 2001].
} 
Сама глава (хотя название «Исторический живописец Иванов» позволяет читателю воспринимать ее, скорее, статьей, а не письмом), тем не менее, также отвечает авторской концепции «Выбранных мест...» как книги писем: она обращена к графу Матвею Юрьевичу Вьельгорскому и открывается недвусмысленно эпистолярной формой упоминания о художнике: «Пишу к вам об Иванове» (VIII, c. 328). Таким образом автор одновременно и вводит основного персонажа главыписьма, и акцентирует внимание читателя на ее документальной природе.

Буквально с первых строк Гоголь обозначает два важных аспекта изображаемой им личности художника: первый - его потенциальную гениальность (упоминание о слухе, «будто художники и все профессора нашей Академии художеств, боясь, чтобы картина Иванова не убила собою все, что было доселе произведено нашим художеством, из зависти стараются о том, чтоб ему не даны были средства на окончание»), второй - обозначение его бедствующего положения («... чтобы не умер над ней с голоду художник,- говорю буквально - не умер с голоду».- VIII, с. 328).

Слово умер повторяется и несколькими строками ниже, уже в принципиально ином значении, обнажающем перед адресатом письма и -шире перед читателем сущность идеального художника, какой видит ее автор: «Он не только не ищет профессорского места и житейских выгод, но даже просто ничего не ищет, потому что уже давно умер для всего в мире, кроме своей работыл (VIII, c. 329). Здесь же вводится и столь важная для Гоголя тема смирения, которая вводит сопоставление образа Иванова с Христианином - принципиально важным образом, проходящим через всю книгу: «Он молит о нищенском содержании < ..> которое дается только начинающему работать ученику, а не о том, которое следует ему, как мастеру, сидящему над таким колоссальным делом, которого не затевал доселе никто» (VIII, с. 329),-- и это показывает масштаб дарования художника, взявшегося за работу невиданной сложности.

В дальнейшем автор последовательно пополняет намеченные выше черты творца, вводя все новые и новые примеры: «...и капля времени у художника не пропала даром [его ответственное отношение к своему труду.- A.E.], что одних этюдов, приготовленных им для картины своей, наберется на целый зал и может составить отдельную выставку, что необыкновенная величина самой картины, которой равной еще не было (она больше картин Брюлова и Бруни) [невиданный масштаб труда.-A.E.], требовала слишком много времени для работы, особенно при тех малых денежных средствах [бедность, недостаток средств и материалов.A.E.], которые не давали ему возможности иметь несколько моделей вдруг, и притом таких, каких бы он хотел <..> Предмет картины <..> слишком значителен. Из евангельских мест взято самое труднейшее для исполнения, доселе еще небранное никем из художников» (VIII, с. 329). То есть бедственное положение художника изображено как пример внешнего влияния, призванного помешать осуществлению его замысла, но которое, однако же, он как творец преодолевает и продолжает «скорбный труд» вопреки всему, производя монументальную работу и руководствуясь при этом, по сути, лишь внутренним стержнем-тем состоянием 
творческого духа, смиренного духа истинного христианина,- что вступает в противоборство с внешним влиянием и одерживает победу над последним. Замечательно в этом отношении также изображаемое Гоголем торжество справедливости в отношении общества к истинному художнику, возникающее не сразу, но, что важно, по прошествии времени: «Доселе раздавался ему упрек в медленности $<\ldots>$ теперь все чувствуют нелепость упрека в медленности и лени такому художнику, который, как труженик, сидел всю жизнь свою над работою и позабыл даже, существует ли на свете какое-нибудь наслажденье, кроме работы» (VIII, c. 329).

Следующим шагом в развитии конструируемого автором образа идеального художника становится обнажение этой самой «сокровенной», внутренней, духовной составляющей его работы («собственное душевное дело», по Гоголю): «Так уже было определено, чтобы над этою картиной совершилось воспитанье собственно художника, как в рукотворном деле искусства, так и в мыслях, направляющих искусство к законному и высшему назначенью» (VIII, с. 329). И вновь автор обозначает два аспекта - две составляющие внутреннего стержня художника: собственно мастерство в его прикладном смысле («рукотворное дело искусства») и грандиозная работа мысли, духовная работа, предшествующая непосредственному исполнению замысла на холсте; причем она, очевидно, воспринимается как более важная, первичная, основополагающая. И это не только способствует творческой эволюции конкретного художника, но и определяет движение самого искусства в целом.

По мере развития авторской мысли становится все более очевидной параллель между Ивановым и самим Гоголем, между работой художника над картиной «Явление Мессии» и работой писателя над «нужной книгой». Так, звучащие в адрес Иванова упреки в медлительности и непонимание со стороны окружающих («Сам же виноват; пусть бы большая картина шла своим чередом, а в промежутках мог бы он работать малые картины, брать за них деньги и не умереть с голода».- VIII, с. 332) были знакомы и Гоголю в период его работы над «Выбранными местами...», о чем он и сообщит в «Авторской исповеди» позднее: «Несколько раз, упрекаемый в недеятельности, я принимался за перо. Хотел насильно заставить себя написать хоть что-нибудь вроде небольшой повести или какого-нибудь литературного сочинения - и не мог произвести ничего» (VIII, c. 445). Причина такого положения и художника, и писателя одна и та же-Гоголь сам формулирует ее в XXIII главе: «...художнику, которому труд его, по воле Бога, обратился в его душевное дело, уже невозможно заняться никаким другим трудом, и нет у него промежутков, не устремится и мысль его ни к чему другому, как он ее ни принуждай и ни насилуй» (VIII, с. 332).

Еще одной проблемой художника становится его неумение ясно, сразу во всей полноте, прозревать замысел грядущего произведения, подсказанный ему провидением: «Неужели ему сказать: “Я произведу одно такое дело, которое вас потом изумит, но которого вам не могу теперь рассказать, потому что многое, покуда, и мне самому еще не совсем понятно...”” (VIII, с. 332). Эта невозможность 
выразить внутренний творческий замысел словами, донести его до окружающих, «стоящих на других поприщах, которые не могут <..> даже постигнуть, что может существовать в искусстве его высшая степень, свыше той, на которой оно стоит в нынешнем модном веке ${ }^{5} »$ (VIII, 332),- и становится причиной отсутствия понимания со стороны общества, неправильной интерпретации поступков художника. Об этом Гоголь не раз упоминает на всём протяжении главы - например, в следующих фрагментах: «...а в это время упрекали его в медленности и торопили его», «...а его в это время укоряли даже знавшие его люди, даже приятели, думая, что он просто ленится, и помышляли серьезно о том, нельзя ли голодом и отнятием всех средств заставить его кончить картину» (VIII, с. 331-332). Но в то же время именно эти негативные факторы, по мысли Гоголя, способствуют полному развитию творца, приближают его к исполнению замысла: «Не будь этих же самых тяжелых его обстоятельств и внутренних терзаний душевных < ..> не изобразить бы ему никогда того, что начинает он уже изображать теперь на полотне» (VIII, с. 333). Движимый Провидением, творец не может избежать этих бедствий, отвлечься от своего дела и заняться временно работой, способной улучшить его положение, но само бедственное положение свое истинный художник способен обратить в подспорье, сделать стимулом творчества и, преодолев преграды, воплотить замысел.

То есть для автора истинный художник - тот, кто способен, преодолевая внешнее противодействие силою творческого духа, не просто осуществить собственный творческий замысел, воплотить в объективной реальности ту мысль, которую сформировало его творческое сознание, но и, в известном смысле, исполнить предначертанное, создать произведение, способное дать толчок развитию мирового искусства. В подтверждение тому - следующие фрагменты: «...я вижу во всем этом волю провиденья», «...душевное дело художника явленье слишком редкое в мире, явленье, в котором вовсе не участвует произвол человека, но воля того, кто повыше человека» (VIII, с. 329).

Кроме того, принципиально важной для Гоголя является идея о необходимости для художника, избравшего своей задачей «изобразить ход обращенья человека ко Христу» (VIII, с. 330), самому пройти этот путь обращения. Для иных художественных произведений прохождение творцом (художником, поэтом, писателем) подобного пути может быть и не обязательным, но сюжет, избранный для своей картины Ивановым, по мысли автора, доступен лишь человеку, лично прошедшему путь преображения. И путь этот представляется сложным и продолжительным, требующим от творца особых усилий. На этой мысли Гоголь счел нужным остановиться: «Есть люди, которые уверены, что великому художнику все доступно < . > все может достаться ему легко, будь только он талантливый художник, да поучись в академии» (VIII, с. 330). Действительно, такая мысль могла бы возникнуть у читателя после восприятия столь масштабно изображенной личности творца. Гоголь предупреждает подобное понимание деятельности художника одной точной и принципиально важной для понимания

\footnotetext{
${ }_{5}^{5}$ Упоминание о высшей степени искусства напрямую соотносится с образом идеального творца. 
образа фразой: «Художник может изобразить только то, что он почувствовал и о чем в голове его составилась уже полная идея; иначе картина будет мертвая, академическая картина» (VIII, с. 330; курсив Гоголя). Идея о чудесном Провидении, одной своей волей направляющем художника и дающем тому если не материальные средства, то все необходимые для осуществления замысла духовные силы, подвергается резкой критике со стороны автора «Выбранных мест...». Данная концепция принципиально важна в гоголевском понимании истинного художника: идет ли речь об Иванове или, позже, о Пушкине 6 ,-это никогда не баловень судьбы, каковым нередко представляется творец обывателю, но всегда суровый и честный труженик, испытывающий все тяготы и лишения по своему призванию, своему делу, преодолевающий сотни преград для воплощения того замысла, который был внушен ему Провидением.

Не менее ярко эта мысль выражена и в XXIII главе: «Но как изобразить то, чему еще не нашел художник образца? <..> Откуда мог он взять его? Из головы? Создать воображеньем? Постигнуть мыслью? Нет, пустяки! Холодна для этого мысль и ничтожно воображенье. Иванов напрягал воображенье, елико мог, старался на лицах всех людей, с какими ни встречался, ловить высокие движенья душевные, оставался в церквях следить за молитвой человека - и видел, что все бессильно и недостаточно и не утверждает в его душе полной идеи о том, что нужно. И это было предметом сильных страданий его душевных <..> Иванов молил Бога о ниспослании ему такого полного обращенья, лил слезы в тишине, прося у него же сил исполнить им же внушенную мысль; а в это время упрекали его в медленности и торопили его!» (VIII, с. 331). Провидение внушает художнику замысел будущего произведения, но лишь истинный художник способен собственным неусыпным трудом, претерпевая тяготы и лишения, исполнить этот замысел в его высшем, идеальном виде,- таковой представляется мысль автора «Выбранных мест...» после внесения им необходимых уточнений в образ идеального творца, воплощенный в книге не абстрактно, а с опорой на личность реально существующего человека. Таким образом Гоголю удается добиться снижения общего пафоса авторского размышления об искусстве и выразить несомненно важную для него как художника идею более доверительным тоном, характерным для избранного им «эпистолярного» жанра. Сама же идея оказывается неразрывно связана с мучительно переживаемой Гоголем проблемой соотношения духовного и собственно эстетического начал в искусстве ${ }^{7}$. Именно размышления над этой проблемой приводят писателя к поиску новой эстетики, отличной от всего предшествующего художественного творчества, к использованию элементов документализма при работе над книгой «Выбранные места из переписки с друзьями» и вторым томом поэмы «Мертвые души» [см. об этом, например: Кораблев, 2013].

\footnotetext{
${ }^{6}$ См., например, в XXXI главе: «Даже и в те поры, когда метался он сам [Пушкин.-A.E.] в чаду страстей, поэзия была для него святыня - точно какой-то храм. Не входил он туда неопрятный и неприбранный; ничего не вносил он туда необдуманного, опрометчивого из собственной жизни своей; не вошла туда нагишом растрепанная действительность» (VIII, c. 382).
}

${ }^{7}$ Подробнее об эстетических взглядах Гоголя и А. А. Иванова см.: [Дилакторская, 2011]. 


\section{СПИСОК ЛИТЕРАТУРЫ}

Александр Андреевич Иванов в письмах, документах, воспоминаниях / Сост. И. А. Виноградов. - Москва : ИД «XXI век-Согласие», 2001. - 776 с.

Боткин, М.Александр Андреевич Иванов : Его жизнь и переписка. 1806-1858 гг. / М. Боткин. - Санкт-Петербург : Тип. М. М. Стасюлевича, 1880. $477 \mathrm{c}$.

Виноградов, И. А. Н. В. Гоголь и А. А. Иванов : К истории создания картины «Явление Мессии» / И. А. Виноградов // Александр Андреевич Иванов в письмах, документах, воспоминаниях. - Москва, 2001. - С. 670-708.

Дилакторская, О. Г. Н. В.Гоголь и А.А.Иванов (к вопросу об эстетической концепции) / О. Г. Дилакторская // Феномен Гоголя : Мат-лы Юбил. междунар. науч. конф., посвящ. 200-летию со дня рождения Н.В.Гоголя. Санкт-Петербург : Петрополис, 2011. -С. 270-281.

Золотусский, И.П.По следам Гоголя / И.П. Золотусский. - Москва : Детская литература, 1988. - 191 с.

Кораблев, А.А. Литературный контекст 1840-х годов в подтексте «Мертвых душ» : Тентетников и его окружение - возможные прообразы и прототипы / А.А.Кораблев // Творчество Гоголя и русская общественная мысль : Тринадцатые Гоголевские чтения. - Москва; Новосибирск : Новосиб. изд. дом, 2013. - С. 230-240.

Переписка Н. В. Гоголя : в 2 т. - Москва : Художественная литература, 1988. - T. 2. -527 c.

\section{REFERENCES:}

Aleksandr Andreevich Ivanov v pis'mah, dokumentah, vospominanijah / Sost. I. A. Vinogradov. - Moskva : ID «XXI vek - Soglasie», 2001. - 776 s.

Botkin, M.Aleksandr Andreevich Ivanov : Ego zhizn' i perepiska. 1806-1858 gg. / M. Botkin. - Sankt-Peterburg : Tip. M. M. Stasjulevicha, 1880. -477 s.

Dilaktorskaja, O.G. N. V. Gogol' i A. A. Ivanov (k voprosu ob jesteticheskoj koncepcii) / O. G. Dilaktorskaja // Fenomen Gogolja : Mat-ly Jubil. mezhdunar. nauch. konf., posvjashh. 200-letiju so dnja rozhdenija N. V. Gogolja. - Sankt-Peterburg : Petropolis, 2011. - S. 270-281.

Korablev, A.A. Literaturnyj kontekst 1840 -h godov v podtekste «Mertvyh dush» : Tentetnikov i ego okruzhenie - vozmozhnye proobrazy i prototipy / A. A. Korablev // Tvorchestvo Gogolja i russkaja obshhestvennaja mysl' : Trinadcatye Gogolevskie chtenija. - Moskva; Novosibirsk : Novosib. izd. dom, 2013. - S. 230-240.

Perepiska N. V. Gogolja : v 2 t. - Moskva : Hud. lit-ra, 1988. - T. 2. -527 s.

Vinogradov, I. A. N. V. Gogol' i A. A. Ivanov : K istorii sozdaniya kartiny «Yavleniye Messii»/ I. A. Vinogradov // Aleksandr Andreyevich Ivanov v pis'makh, dokumentakh, vospominaniyakh. - S. 670-708.

Zolotusskij, I. P. Po sledam Gogolja / I. P. Zolotusskij. - Moskva : Det. lit-ra, 1988. - $191 \mathrm{~s}$. 